\title{
Molecular detection and immunopathological examination of Deltapapillomavirus 4 in skin and udder of Egyptian cattle
}

\author{
Emad Beshir Ata ${ }^{1}$, Mohamed Abd El-Fatah Mahmoud ${ }^{1}$ and A. A. Madboli²
}

1. Department of Parasitology and Animal Diseases, Veterinary Research Division, National Research Center, 12622 Dokki, Giza, Egypt; 2. Department of Animal Reproduction and Artificial Insemination, Veterinary Research Division, National Research Center, 12622 Dokki, Giza, Egypt.

Corresponding author: Emad Beshir Ata, e-mail: emadvet2003@gmail.com

Co-authors: MAEM: m_elfatatri@yahoo.com, AAM: abdelnasser_mazen_monzer@yahoo.com

Received: 18-03-2018, Accepted: 29-05-2018, Published online: 10-07-2018

doi: 10.14202/vetworld.2018.915-920 How to cite this article: Ata EB, Mahmoud MAE,Madboli AA (2018) Molecular detection and immunopathological examination of Deltapapillomavirus 4 in skin and udder of Egyptian cattle, Veterinary World, 11(7): 915-920.

\begin{abstract}
Aim: Bovine papillomaviruses (BPVs) are the main cause of bovine papillomatosis resulting in cutaneous and/or mucosal benign tumors that could be transformed to malignant ones with marked economic importance, especially in the dairy farms. Molecular, pathological, and immunohistochemical (IHC) diagnosis of bovine papillomatosis cases was conducted to identify and characterize the circulating BPV genotype in some Egyptian governorates.
\end{abstract}

Materials and Methods: Wart-like lesions in skin, udder, and teats were collected from 123 infected cases in Giza, Beni Suef, and El Menoufia Governorates, Egypt, during 2016-2017. Pathological and IHC characterization, molecular identification, genotyping, and phylogenetic analysis based on the conserved late (L1) gene of the all samples were carried out.

Results: 89 of the 123 collected samples (72.3\%) were positively detected by polymerase chain reaction (PCR). The sequence analysis of the obtained PCR amplicons was identical revealing identification and genotyping of only one type (Deltapapillomavirus 4 isolate EGY 2017) with accession number (MG547343) which found to be closely related to the recently detected Deltapapillomavirus 4 isolate 04 asi UK (accession no. MF384288.1) and isolate Deltapapillomavirus 4 isolate 25_equ_CH (accession no. MF384286.1) with 99\% nucleotide sequence identity. Histopathological examination revealed severe hyperkeratosis in stratum corneum and acanthosis in most of the cases. These tissue changes were confirmed by the presence of golden brown stained proliferating cell nuclear antigen which was localized intranuclear and perinuclear in other cells using IHC Technique.

Conclusion: It is the first time to detect and genotype the BPVs in these areas with no record of previous genotyping in the whole country. The obtained results will highlight the importance of this disease.

Keywords: bovine papillomaviruses, characterization, Egypt, genotyping, immunohistochemical, pathological, phylogeny.

\section{Introduction}

The benign skin and mucous membrane warts are mainly caused by the epitheliotropic papillomaviruses (PVs) [1], which are small, non-enveloped, double-stranded DNA viruses with circular genomes [2]. According to the conserved late (L1) gene, the most common 13 BPVs types are found in the four genera Xipapillomavirus, Deltapapillomavirus, Epsilonpapillomavirus, and Dyoxipapillomavirus [1,3].

The disease has a worldwide distribution in many areas of the world including America, Europe, and Asia [4,5]. It results in notable economic losses in both of the dairy and beef industries [6]. Teat papillomatosis results in dairy herd problems because of milking process difficulties as a result of ulceration and rupture of the cutaneous lesions which acts as

Copyright: Ata, et al. Open Access. This article is distributed under the terms of the Creative Commons Attribution 4.0 International License (http://creativecommons.org/licenses/by/4.0/), which permits unrestricted use, distribution, and reproduction in any medium, provided you give appropriate credit to the original author(s) and the source, provide a link to the Creative Commons license, and indicate if changes were made. The Creative Commons Public Domain Dedication waiver (http://creativecommons.org/ publicdomain/zero/1.0/) applies to the data made available in this article, unless otherwise stated. predisposing factors for mastitis and distortion of the milk ducts [7].

Infection to other animals might occur through milk, semen, and urine or vertically transmitted to the offspring [8]. It was reported that coinfection with different BPV types might occur in the same animal [1]. Although PVs are highly host-specific that usually do not cross species barriers, new variants could evolve if mutations accumulate within the virus genome. Highly related PVs were detected in different host species representing the possibility of cross-species infection, which may result in the emergence of new types [9]. The virus can infect different bovine types, but buffalo infection is less common than cattle [10].

The predilection seats of the developed benign cutaneous tumors are the haired skin, teats, penis, and vulva. Hence, the clinical condition of the infected animals varies according to the affected site $[11,12]$.

Identification and molecular characterization of BPV types are important for the disease control. Molecular techniques remain important tools for diagnostic purposes, particularly in determining asymptomatic carriers within the herd $[1,13]$. Few studies about the situation of this virus in Egypt focus 
mainly on histopathological examination [14] and different treatment regimens of the resulted surgical wounds [15]. Meanwhile, the virus was successfully isolated on fetal bovine skin tissue culture and embryonated chicken eggs without complete identification, and it was suspected to be BPV of type II [16].

In the present study, molecular, pathological, and immunohistochemical (IHC) diagnosis of bovine papillomatosis cases was conducted to identify and genotype the circulating BPV genotype in some Egyptian governorates.

\section{Materials and Methods}

\section{Ethical approval}

The experiments were carried out in accordance with the guidelines laid down by the National Research Center, Animal Ethics Committee and in accordance with local laws and regulations (NO. 17101).

\section{Study area and animals samples}

The samples were collected from eight different farms, six slaughterhouses, and three veterinary clinics at three different Egyptian governorates (Giza, Beni Suef, and El Menoufia) in the period between March 2016 and July 2017. A total of 123 wart lesions were used in this study. The animals under this experiment were of different ages and sex with wart lesions of variable sizes at different locations in the body including head, neck, thighs, udder, and teats (Figure-1). The wart lesion biopsies were collected using local anesthesia $2 \%$ lidocaine (lidocaine HCL, Pharco B ${ }^{\circledR}$ ) under aseptic condition. Each specimen was divided into two portions; the first one was used for molecular identification, while the second portion was used for histopathological and IHC analysis.

\section{Molecular identification}

The viral DNA was extracted from the wart lesion according to the instruction manual of (QIAamp ${ }^{\circledR}$ DNA Mini Kit, Qiagen $\mathrm{GmBH}$ ). The final eluted DNA was quantified spectrophotometrically and preserved

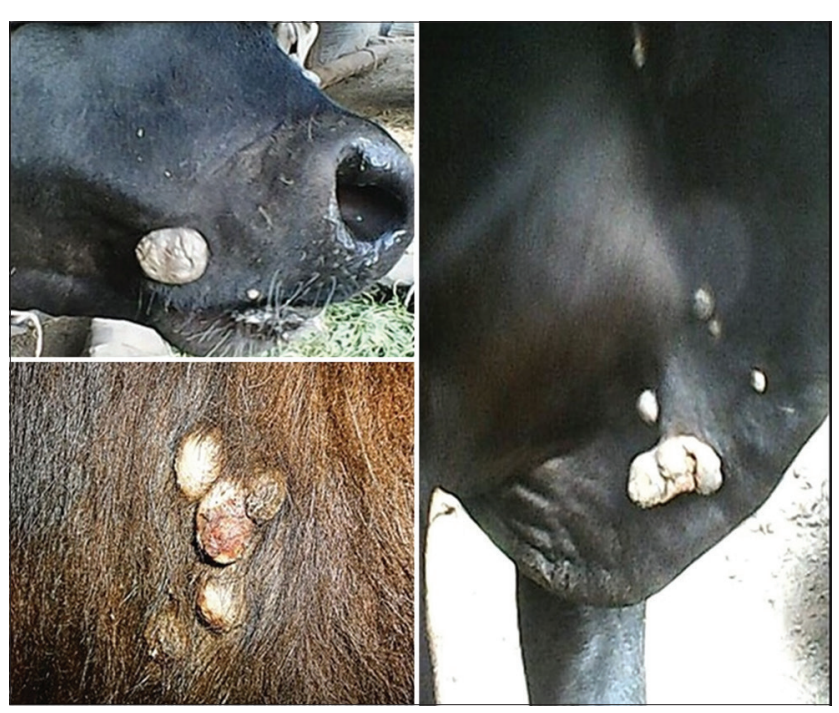

Figure-1: Macroscopic view of wart lesions at different locations of animal bodies. at $-20^{\circ} \mathrm{C}$ for further experiments. The polymerase chain reaction (PCR) conditions were initial denaturation at $95^{\circ} \mathrm{C}$ for $5 \mathrm{~min}$, followed by 35 cycles consisting of denaturation at $95^{\circ} \mathrm{C}$ for $30 \mathrm{~s}$, annealing at $55^{\circ} \mathrm{C}$ for $30 \mathrm{~s}$, and extension at $72^{\circ} \mathrm{C}$ for $1 \mathrm{~min}$, while the final cycle was elongation at $72^{\circ} \mathrm{C}$ for 5 min using the MY09 (5-GCMCAGGGWCATAAYAATGG-3) and MY011 (5 CGTCCMARRGGAWACTGATC-3) primers [17]. The PCR products were visualized on ethidium bromide stained $1.5 \%$ agarose gel.

\section{Sequencing and phylogenetic analysis}

The obtained PCR amplicons were purified according to the manufacturer's instructions of the QIAquick PCR Purification Kit, Qiagen, before being sent for sequencing. Bioedit software (Version7.2); (http://bioedit.software.informer.com/7.2/) was used for sequence assembly and editing. The obtained sequence was deposited at the Gene Bank with an accession number (MG547343). The free Basic Local Alignment Search Tool of the National Center for Biotechnology Information https://blast.ncbi.nlm.nih. gov/Blast.cgi was used for the comparison with the similar sequences.

The evolutionary history was inferred using the maximum likelihood method based on the TamuraNei model [18]. The analysis involved 29 nucleotide sequences. All positions containing gaps and missing data were eliminated. Evolutionary analyses were conducted using MEGA7 [19]. The confidence level of the tree was assessed by bootstrapping using 1000 replicates.

\section{Histopathological examination}

The collected tissue samples were fixed in $10 \%$ neutral buffer formalin (NBF). Tissue specimens were embedded in paraffin, processed, sectioned at the 3-5 $\mu \mathrm{m}$ thickness, and stained with $\mathrm{H}$ and $\mathrm{E}$ for the detection of the histopathological changes [20].

\section{IHC examination}

Tissue specimens were fixed in $10 \%$ NBF overnight, then transferred into ethanol $70 \%$ (to keep the antigenicity of the virus particle), then deparaffinized, sectioned at $3 \mu \mathrm{m}$ thickness, and mounted on positively charged slides. Streptavidin/biotin/peroxidase complex $(\mathrm{ABC})$ detection kit fromScyTek Laboratories, USA, was used. The kit was species specified as anti-mouse and anti-rabbit. Antigen retrieval was done using proteinase $\mathrm{K}$ enzyme $0.1 \%$. Tested samples were incubated with rabbit polyclonal anti-BPV1 antibody as anti-proliferating cell nuclear antigen (anti-PCNA) imported from ScyTek Laboratories, USA. Tested sections were faintly counterstained with Mayer's hematoxylin stain and examined under light microscopy [21].

\section{Results}

Molecular identification and sequencing analysis

Partial amplification of the L1 gene was successfully detected in 89 of the 123 collected samples $(72.3 \%)$ with the size of an expected band around 
$450 \mathrm{bp}$ (Figure-2). The sequence analysis of the obtained PCR amplicons was the identical revealing

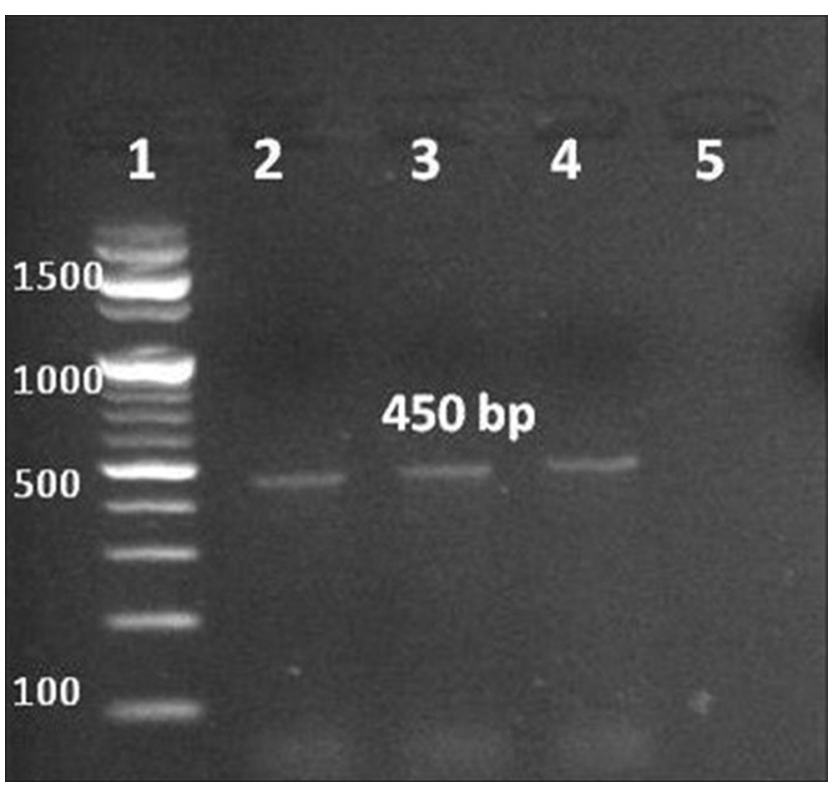

Figure-2: Molecular detection of bovine papillomavirus in bovine wart samples. Partial L1 gene was amplified using My09 and My011 primers set; ethidium bromide stained $1.5 \%$ agarose gel electrophoresed in TE buffer was used for visualization. L1: 100 bp Marker (Intron Scientific), L2-L4: specific 450 bp band representing positive samples, and L5: negative sample. identification of only one type (Deltapapillomavirus 4 isolate EGY 2017). The obtained blast result showed 99\% homology with the Deltapapillomavirus 4 isolate 04 asi UK (accession no. MF384288.1), Deltapapillomavirus 4 isolate 25_equ_CH (accession no. MF384286.1), and BPV SY-12 strain (accession no. KX271663.1). They were evolved from the same ancestor as shown in the phylogenetic rooted cladogram (Figure-3), the obtained sequences were found to belong to Deltapapillomavirus 4; BPV type-1. To the best of our information, this is the first study to identify and characterize the presence of BPV-1 in Egypt.

\section{Histopathological findings}

A total number of 82 tissue samples from the examined wart lesions (123 samples) showed severe hyperkeratosis in stratum corneum which appeared as finger-like projections (Figure-4a) associated with severe acanthosis (increase in the thickness of the stratum spinosum of the epidermis) (Figure-4a-c). In addition to the hyperkeratosis, 48 cases of the 123 examined cases exhibited severe hyperplasia in the stratum granulosum leading to widening of the distance between the corneal layer and the other layers. The areas of overgrowth were invaded by trabeculae from the upper corneal layer (Figure-4d). Other 24 cases showed multiple hyperplastic masses

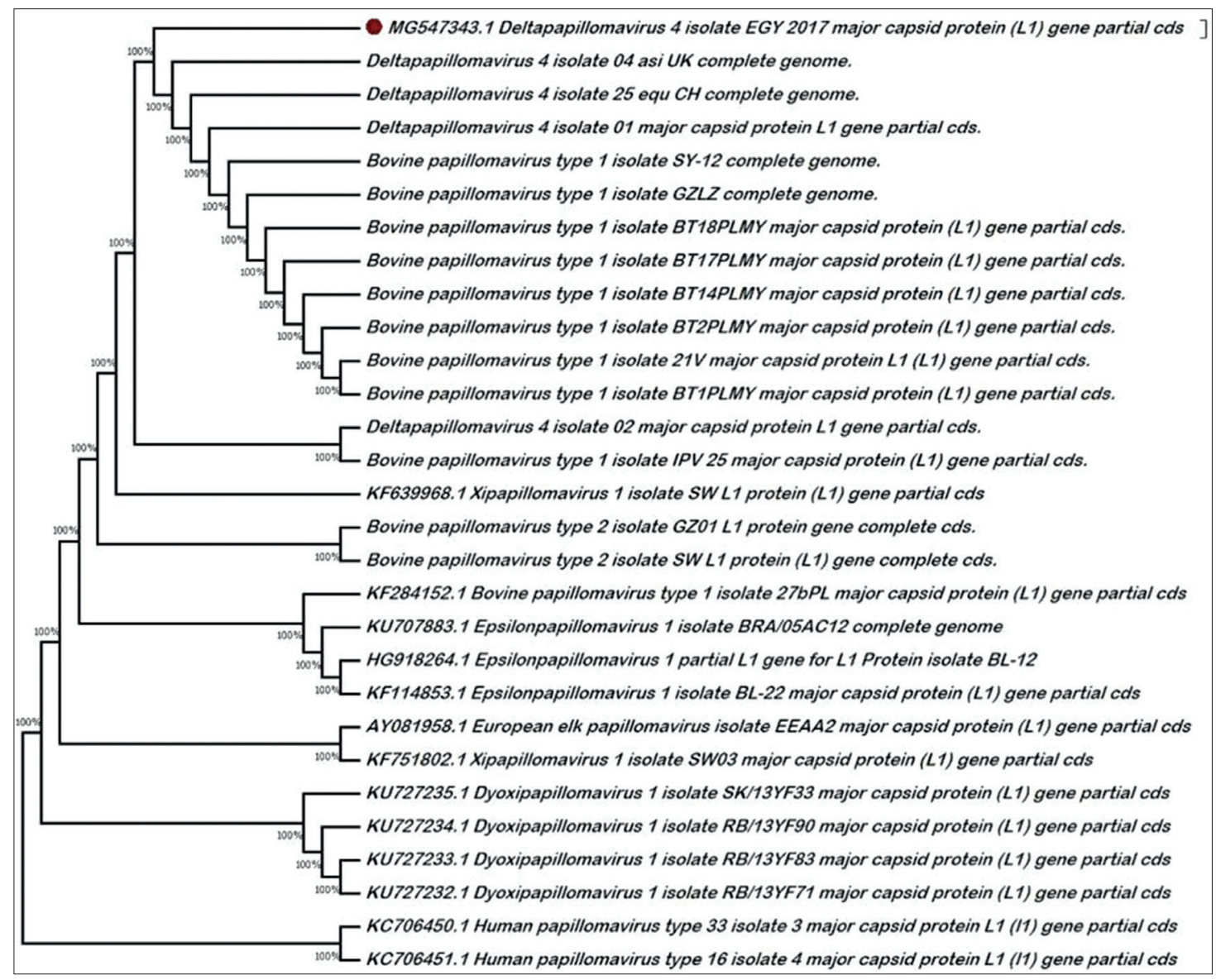

Figure-3: The phylogenetic rooted tree created by MEGA 7 software. The evolutionary history was inferred using the maximum likelihood method based on the Tamura-Nei model. The confidence level of the NJ tree was assessed by bootstrapping using 1000 replicates. The red circle indicates the sequence obtained in this study. 


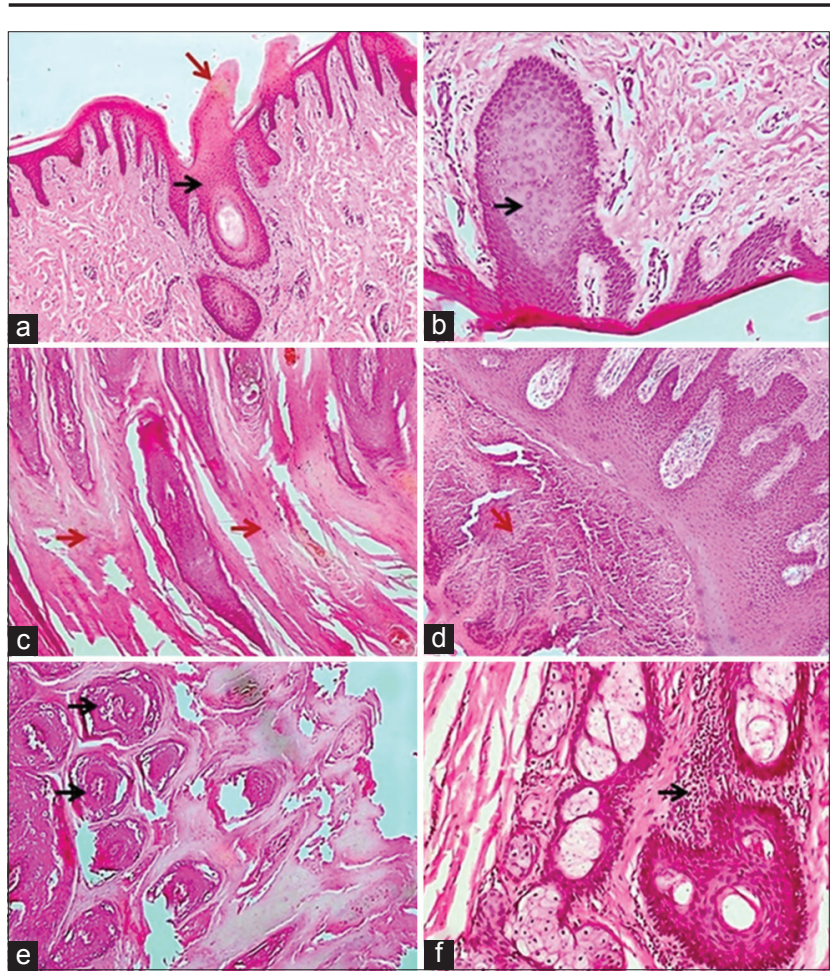

Figure-4: Histopathological examination of the wart lesions. Warts in skin and udder of cows infected with bovine papillomavirus type 1 (BPV-1) showed hyperkeratosis in stratum corneum (red arrow) associated with severe acanthosis in stratum spinosum (black arrow) (a and c: $100 \times$; b: $200 \times$ ). Severe hyperplasia in the stratum granulosum which invaded by trabeculae came from the corneal layer (red arrow) (d). Multiple hyperplastic masses of the epidermal layer invaded the stratum corneum (black arrows) (e). Moderate focal periglandular aggregation of mononuclear inflammatory cells was found (f: $200 \times$ ). Tissue specimens stained with hematoxylin and eosin stain.

in stratum spinosum that invaded the stratum corneum (Figure-4e) and also exhibited moderate focal periglandular aggregation of mononuclear inflammatory cells (Figure-4f).

\section{IHC findings}

Sixty-nine cases of a total number of 123 examined cases showed a strong positive immunoreactive result for the presence of the PCNA antigen of BPV with moderate golden brown intensity using $\mathrm{ABC}$ technique. The golden brown stained PCNA antigen was localized intranuclear as shown in Figure-5a and $b$ and perinuclear in other cells as shown in Figure 5c and $\mathrm{d}$ in the stratum germinativum and stratum spinosum.

\section{Discussion}

BPVs are classified under the Papillomaviridae family, which infect the epithelium and mucosa of different animals resulting in benign hyperproliferative lesions [3]. Studding of BPV is very important not only due to its economic importance $[6,22]$ but also to the fact that it has represented one of the most extensively studied animal models of viral carcinogenesis, especially, that the resulted benign tumors could be transformed to malignant ones in cases of immune suppression [23,24].

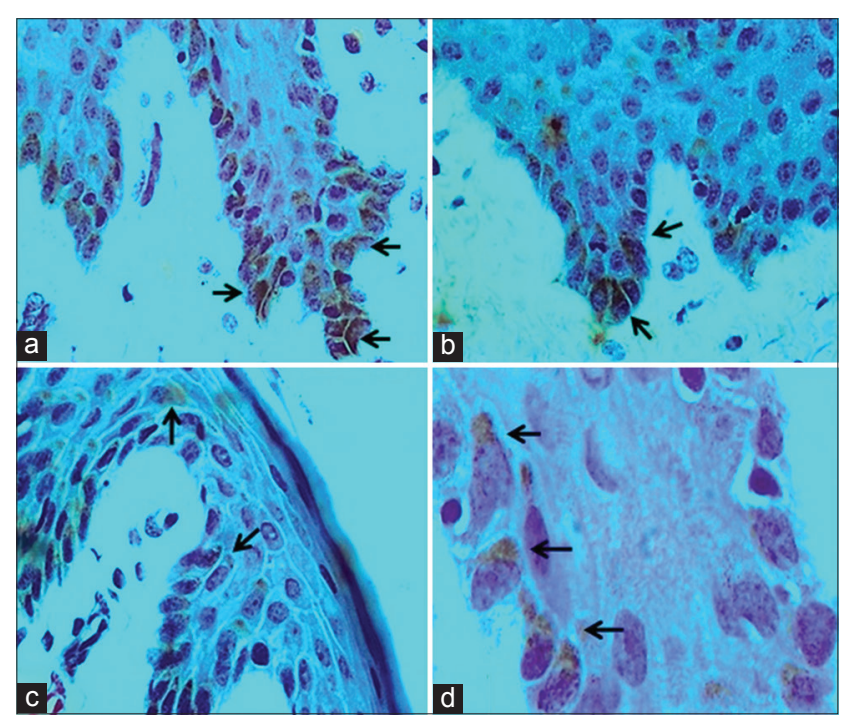

Figure-5: Immunohistochemistry detection of bovine papillomavirus type 1 (BPV-1) proliferating cell nuclear antigen (PCNA). Immunohistochemistry detection of PCNA antigen of BPV-1 by avidin-biotin complex technique was achieved in the examined skin and udder warts. Moderate intensity of golden brown stained BPV antigen was detected intranuclear as in a and b: $400 \times$. In other sites, the BPV antigen found as capping to the nuclear membrane of stratum germinativum and stratum spinosum (c: $400 \times$ and d: $1000 \times$ ). The intensity of viral antigen was high in cells of stratum germinativum more than stratum spinosum. Tissue specimens were counterstained with hematoxylin stain.

Concerning the obtained results, it was noticed that all of the infected cases were cattle while there were no clinical cases of buffaloes and this agrees with that recorded by Jangir et al. [25] and Somvanshi [26]. Although there are many successive trials of identification and characterization of some BPVs in buffalos $[27,28]$, especially that cross-species infection was recorded in cases within mixed herd systems [29].

The lesions were found in different parts of the animal body including teats, haired and hairless areas; this is in accordance with Corteggio et al. [11], and Munday [12] who cleared that condition of the infected animal correlates with infected sites.

The percentage of the positive confirmed cases using the MY primer set was 72.3\% (89/123), and nearly the same result $77.1 \%(27 / 35)$ was previously recorded by Dagalp et al. [1] while $86.42 \%$ (121/140) was recorded by Hamad et al. [13]. On the other hand, 36\% (19/52) and 53\% (8/15) of positivity were recorded by Rojas-Anaya et al. [10] and Ogawa et al. [17], respectively. Although the high sensitivity of the PCR as a diagnostic tool but molecular detection of all samples might not occur, or false negative results could be obtained in case of presence of low copy number of viral DNA or multiple type infections in the same samples [30]. Using of the MY primer set in the detection of PVs in previous studies showed high specificity and sensitivity than the other GP5+/GP6+ [31] or the SPF10 primer sets [32], with superiority in successful detection of multiple PVs 
types in one sample $[31,33]$. It was recorded that the sensitivity of the MY set was $90 \%$ in some studies which recommended using of such set in the screening of the PVs [31,32].

The sequence analysis of the positive DNA samples revealed the detection of BPV-1 which is the most detected type in different countries $[2,34]$. It has the ability to infect other species including equine, asinine, and bovine hosts that become a common phenomenon [35]. According to the general criteria and rules used for PV taxonomy, a new genotype is considered if the comparison with the closest strain revealed variance more than $10 \%$ of the L1 gene nucleotide sequence [36]. Therefore, the obtained isolate in this study is considered to be Deltapapillomavirus 4 as it resembles $99 \%$ homologous to the Deltapapillomavirus 4 isolate 04_asi_UK strain.

The IHC findings showed that the tissue reaction against $\mathrm{BPV}-1$ infection is proliferative where the main changes arehyperkeratosis in corneal layer and hyperplasia in stratum spinosum and granulosum are confirmed by the detection and localization of PCNA antigen by IHC protocol. Our results come in accordance with Maeda et al. [37] who reported that the hallmark lesions of BPV-1 infection are proliferative as epithelial hyperplasia and acanthosis. This proliferation could be explained by the presence of PCNA antigen of BPV which is implicated in the endothelial cell proliferation, angiogenesis, and vascular permeability. Moreover, the underlying skin layer of infected cows contains minute focal aggregations of mononuclear inflammatory cells although the tissue cells are often histologically normal [12].

It is worth noting that genotyping of the PV local strain is highly important, especially that prophylactic vaccines have been used in many parts of the world to prevent and eventually treat infections [38]. The present study is the first one to identify and genotype the presence of BPV-1 in these areas with no record of genotyping in the whole country. The obtained results will highlight the importance and increase the attention and awareness of such infectious disease to implement the best control measures.

\section{Conclusion}

Molecular identification, pathological and IHC characterization, and genotyping of bovine papillomatosis cases were successfully carried out. Amplification of $\mathrm{L} 1$ gene deduced $72.3 \%$ positivity of the tested samples. Genotyping and phylogenetic analysis revealed identification of Deltapapillomavirus 4 for the first time in Egyptian native breed cattle. Using of PCR in the detection of BPV is more sensitive than the histopathological and/or the IHC examination. A whole country well-structured molecular survey using two different sets of primers should be implemented to determine any other types found in Egypt.

\section{Authors' Contributions}

EBA, AAM, and AAM designed the study and collected the samples. EBA and MAM carried out the molecular diagnosis and the phylogenetic analysis, and MAA conducted the histopathological and IHC examination. All authors analyzed the data, drafted the manuscript, and approved the final manuscript.

\section{Acknowledgments}

The authors would like to thank Assistant Professor Dr. Khaled Abdel Rahman for his valuable help in the phylogenetic analysis. This research work was funded by the authors.

\section{Competing Interests}

The authors declare that they have no competing interests.

\section{References}

1. Dagalp, S.B., Dogan, F.F., Farzani, T.A., Salar, S. and Bastan, A. (2017) The genetic diversity of bovine papillomaviruses (BPV) from different papillomatosis cases in dairy cows in Turkey. Arch. Virol., 162(6): 1507-1518.

2. Silva, M.S.E., Weiss, M., Brum, M.C.S., Dos Anjos, B.L., Torres, F.D., Weiblen, R. and Flores, E.F. (2010) Molecular identification of bovine papillomaviruses associated with cutaneous warts in southern Brazil. J. Vet. Diagn. Invest., 22(4): 603-606.

3. Bernard, H.U., Burk, R.D., Chen, Z., Van doorslaer, K., Hausen, H.Z. and De Villiers, E.M. (2010) Classification of papillomaviruses (PVs) based on 189 PV types and proposal of taxonomic amendments. Virology., 401(1): 70-79.

4. Da Silva, F.R.C., Daudt, C., Streck, A.F., Weber, M.N., Filho, R.V.L., Driemeier, D. and Canal, C.W. (2015) Genetic characterization of amazonian bovine papillomavirus reveals the existence of four new putative types. Virus. Genes., 51(1): 77-84.

5. Savini, F., Gallina, L., Alberti, A., Muller, M. and Scagliarini, A. (2016) Bovine papillomavirus Type 7 in Italy: Complete genomes and sequence variants. Virus. Genes., 52(2): 253-260.

6. Ataseven, V.S., Kanat, O. and Ergun, Y. (2016) Molecular identification of bovine papillomaviruses in dairy and beef cattle: First description of Xi-and Epsilonpapillomavirus in Turkey. Turk. J. Vet. Anim. Sci., 40: 757-763.

7. Tozato, C.C., Lunardi, M., Alfieri, A.F., Otonel, R.A., Di Santis, G.W., de Alcântara, B.K., Headley, S.A. and Alfieri, A.F. (2013) Teat papillomatosis associated with bovine papillomavirus types $6,7,9$, and 10 in dairy cattle from Brazil. Braz. J. Microbiol., 44(3): 905-909.

8. Lindsey, C.J., Almeida, M.E., Vicari, C.F., Carvalho, C., Yaguiu, A., Freitas, A.C., Becak, W. and Stocco, R.C. (2009) Bovine papillomavirus DNA in milk, blood, urine, semen, and spermatozoa of bovine papillomavirus-infected animals. Gent. Mol. Res., 8(1): 310-318.

9. Gottschling, M., Goker, M., Stamatakis, A., BinindaEmonds, O.R., Nindl, I. and Bravo, I.G. (2011) Quantifying the phylodynamic forces driving papillomavirus evolution. Mol. Biol. Evol., 28(7): 2101-2113.

10. Rojas-Anaya, E., Cantú-Covarrubias, A., Alvarez, J.F. and Loza-Rubio, E. (2016) Detection and phylogenetic analysis of bovine papillomavirus in cutaneous warts in cattle in Tamaulipas, Mexico. Can. J. Vet. Res., 80(4): 262-268.

11. Corteggio, A., Altamura, G., Roperto, F. and Borzacchiello, G. (2013) Bovine papillomavirus e5 and e7 oncoproteins in naturally occurring tumors: Are two better than one? Infect. Agent. Cancer., 8(1): 1. 
12. Munday, J.S. (2014) Bovine and human papillomaviruses. Vet. Pathol., 51(6): 1063-1075.

13. Hamad, M.A., Al-Shammari, A.M., Odisho, S.M. and Yaseen, N.Y. (2016) molecular and phylogenetic analysis of bovine papillomavirus Type 1: First report in Iraqi cattle. Adv. Virol., 2016: 1-7.

14. Gaballah, M. (1993) Fibropapillomatosis of the skin and external genitalia of Friesian cattle. J. Egypt. Comp. Pathol. Clin. Pathol., 6: 312-318.

15. Salib, F.A. and Farghali, H.A. (2011) Clinical, epidemiological and therapeutic studies on bovine papillomatosis in Northern oases, Egypt in 2008. Vet. World, 4(2): 53-59.

16. Eisa, M.I., Kandeel, A., El-Sawalhy, A.A. and El-Fetouh, M.S. (2000) Some studies on bovine papillomavirus infection in cattle with trials of its treatment. Vet. Med. J. Giza, 48: 47-55.

17. Ogawa, T., Tomita, Y., Okada, M., Shinozaki, K., Kubonoya, H., Kaiho, I. and Shirasawa, H. (2004) Broadspectrum detection of papillomaviruses in bovine teat papillomas and healthy teat skin. J. Gen. Virol., 85(8): 2191-2197.

18. Tamura, K. and Nei, M. (1993) Estimation of the number of nucleotide substitutions in the control region of mitochondrial DNA in humans and chimpanzees. Mol. Biol. Evol., 10(3): 512-526.

19. Kumar, S., Stecher, G. and Tamura, K. (2016) Mega7: Molecular evolutionary genetics analysis version 7.0 for bigger datasets. Mol. Biol. Evol., 33(7): 1870-1874.

20. Suvarna, K., Layton, C. and Bancroft, J. (2012) Theory and Practice of Histological Techniques. $7^{\text {th }}$ ed. Churchill Livingstone, New York. p1-645.

21. Haines, D.M. and Clark, E.G. (1991) Enzyme immunohistochemical staining of formalin-fixed tissues for diagnosis in veterinary pathology. Can. Vet. J., 32(5): 295-302.

22. Santos, E.U., Silva, M.A., Pontes, N.E., Coutinho, L.C., Paiva, S.S., Castro, R.S. and Freitas, A.C. (2016) Detection of different bovine papillomavirus types and co-infection in bloodstream of cattle. Transbound. Emerg. Dis., 63(1): e103-e108.

23. Venuti, A., Paolini, F., Nasir, L., Corteggio, A., Roperto, S., Campo, M.S. and Borzacchiello, G. (2011) Papillomavirus e5: The smallest oncoprotein with many functions. Mol. Cancer., 10: 140.

24. Bocaneti, F., Altamura, G., Corteggio, A., Velescu, E., Roperto, F. and Borzacchiello, G. (2016) Bovine papillomavirus: New insights into an old disease. Transbound. Emerg. Dis., 63(1): 14-23.

25. Jangir, B.L., Bind, R.B., Kumar, P. and Somvanshi, R. (2017) Pathological studies and detection of different bovine papillomavirus types in buffalo cutaneous warts. Turk. J. Vet. Anim. Sci., 41: 306-311.

26. Somvanshi, R. (2011) Papillomatosis in buffaloes: A lessknown disease. Transbound. Emerg. Dis., 58(4): 327-332.

27. Maiolino, P., Ozkul, A., Sepici-Dincel, A., Roperto, F., Yücel, G., Russo, V., Urraro C., Lucà, R., Riccardi, M.G.,
Martano, M., Borzacchiello, G., Esposito, I. and Roperto, S. (2013) Bovine Papillomavirus Type 2 infection and microscopic patterns of urothelial tumors of the urinary bladder in water buffaloes. Biomed. Res. Int., 2013: 1-6.

28. Roperto, S., Russo, V., Ozkul, A., Corteggio, A., SepiciDincel, A., Catoi, C., Esposito, I., Riccardi, M.G., Urraro, C., Lucà, R., Ceccarelli, D.M, Longo, M. and Roperto, F. (2013) Productive infection of bovine papillomavirus Type 2 in the urothelial cells of naturally occurring urinary bladder tumors in cattle and water buffaloes. PLoS One, 8(5): e62227.

29. Silvestre, O., Borzacchiello, G., Nava, D., Iovane, G., Russo, V., Vecchio, D., D'ausilio, F., Gault, E.A., Campo, M.S. and Paciello, O. (2009) Bovine papillomavirus Type 1 DNA and e5 oncoprotein expression in water buffalo fibropapillomas. Vet. Pathol., 46(4): 636-641.

30. Brandstetter, T., Böhmer, S., Prucker, O., Bissé, E., Zur Hausen, A., Alt-Mörbe, J. and Rühe, J. (2010) A polymer-based DNA biochip platform for human papillomavirus genotyping. J. Virol. Methods, 163(1): 40-48.

31. Qu, W., Jiang, G., Cruz, Y., Chang, C.J. and Ho, G.Y. (1997) PCR detection of human papillomavirus: Comparison between MY09/MY11 and GP5+/GP6+primer systems. $J$. Clin. Microbiol., 35(6): 1304-1310.

32. Szostek, S., Klimek, M., Zawilinska, B., Rys, J., Kopec, J. and Daszkiewicz, E. (2006) Detection of human papillomavirus in cervical cell specimens by hybrid capture and PCR with different primers. Acta Biochim. Pol. 53(3): 603-607.

33. Camargo, M., Soto-De Leon, S., Sanchez, R., Munoz, M., Vega, E., Beltran, M., Perez-Prados, A., Patarroyo, M.E. and Patarroyo, M.A. (2011) Detection by PCR of human papillomavirus in Colombia: Comparison of GP5+/6+ and MY09/11 primer sets. J. Virol. Methods, 178(1-2): 68-74.

34. Lunardi M., De Alcântara B.K., Otonel R.A., Rodrigues, W.B., Alfieri, A.F. and Alfieri, A.A. (2013) Bovine papillomavirus Type 13 DNA in equine sarcoids. $J$. Clin. Microbiol., 51(7): 2167-2171.

35. Koch, C., Ramsauer, A.S., Drögemüller, M., Ackermann, M., Gerber, V. and Tobler, K. (2018) Genomic comparison of bovine papillomavirus 1 isolates from bovine, equine and asinine lesional tissue samples. Virus Res., 244: 6-12.

36. De Villiers, E.M., Fauquet, C., Broker, T.R., Bernard, H.U. and Zur Hausen, H. (2004) Classification of papillomaviruses. Virology, 324: 17-27.

37. Maeda, Y., Shibahara, T., Wada, Y., Kadota, K., Kanno, T., Uchida, I. and Hatama, S. (2007) An outbreak of teat papillomatosis in cattle caused by bovine papilloma virus (BPV) Type 6 and unclassified BPVs. Vet. Microbiol., 121(3-4): 242-248.

38. Lunardi, M., De Camargo T.C., Alfieri, A.F., De Alcântara, B.K., Vilas-Boas, L.A., Otonel, R.A., Headley, S.A. and Alfieri, A.A. (2016) Genetic diversity of bovine papillomavirus types, including two putative new types, in teat warts from dairy cattle herds. Arch. Virol., 161(6): 1569-1577. 